\title{
Evaluation of Public Perception, Awareness and Attitude towards Dental Implant in Punjab Using Web-Based Questionnaire Technique
}

\author{
Singh SK ${ }^{1 *}$, Sharma $\mathrm{P}^{1}$, Jindal $\mathbf{V}^{1}$, Malhotra $\mathrm{D}^{2}$, Bansal $\mathbf{R}^{2}$, Chauhan $\mathrm{P}^{1}$, \\ Singh $\mathrm{A}^{3}$ and Jairth $\mathrm{A}^{4}$ \\ ${ }^{1}$ Department of Periodontics \& Implantology, Himachal Dental College, India \\ ${ }^{2}$ Department of Oral \& Maxillofacial Surgery, Himachal Dental College, India \\ ${ }^{3}$ Department of Conservative Dentistry and Endodontics, Baba Jaswant Singh Dental College \\ and Hospital, India
}

Research Article

Volume 5 Issue 3

Received Date: June 17, 2020

Published Date: July 01, 2020

DOI: $10.23880 /$ oajds-16000260

${ }^{4}$ Department of Department of Prosthodontics and Crown \& Bridge, Desh Bhagat Dental

College and Hospital, India

*Corresponding author: ShubhKarmanjit Singh Bawa, Department of Periodontics, Himachal Dental College, Sundernagar, Himachal Pradesh 175002, India, Tel: +919882051021; Email: skbawa911@gmail.com

\section{Abstract}

Background: In developing nations like India awareness and education about dental implants as a treatment modality is still scanty.

Aim: The study was conducted to determine the perception, awareness of patients toward dental implants as a treatment modality among the general population of Punjab and to assess attitude on accepting dental implants as a treatment modality. Materials and Methods: A structured questionnaire web based survey (via Google Forms) was conducted on 250 randomly selected participants through platform like whatsapp and facebook and assessed using percentage. The participants who agreed opened the link and filled out the form were included in the study.

Results: A total of 240 individuals completed the questionnaires out of which $92 \%$ of the participants were aware of dental implants. Dentists are the main source of information on dental implants followed by internet. Awareness percentage was significantly higher among males and among those whose education level was graduation and above. 58.4\% of the participants regarded high cost of treatment as biggest disadvantage. $44.8 \%$ of the individuals blamed poor maintenance for the failure of implants while $42.6 \%$ of the individuals thought implants would last 10 years. $90.3 \%$ of the participants were ready to restore their loss teeth with dental implants.

Conclusion: This study revealed a high level of awareness among public. Special measures should be made to reduce the cost of dental implants to a more affordable rate.

Keywords: Dental implants; Public acceptance; Information sources; Perception; Awareness; Attitude; Punjab

\section{Introduction}

An adequate dentition is of great importance for wellbeing and life quality. Apart from all the advancements in dentistry, edentulism is still a major public health problem worldwide. Loss of some teeth is called as partial edentulism, whereas loss of all teeth is called as complete edentulism.
Tooth loss is usually accompanied by bone loss and bone loss is four times more in mandible than maxilla. Because of bone loss the facial appearance is also affected which may further cause social disability. Various other functions are also lost with tooth loss for eg. Impaired masticatory function, unhealthy diet and poor oral health quality of life. Therefore to restore the missing teeth, a number of prosthetic techniques 
have been proposed for eg. removable partial dentures, fixed partial dentures. These conventional techniques had their own limitations such as these devices can cause eating difficulties, psychological problems and problems related to aesthetics, retention and stability of prosthesis and a greater amount of risk of the sacrifice of the adjacent healthy tooth structures. To conquer these limitations, dental implant came into existence.

Dental implants have now been used for more than half a century with a very high success rate. Currently, dental implants are commonly recognised as a complete or partially edentulous treatment of patients with prosthetics. This has led to massive acknowledgement and prominence of dental implants in the professional dental community [1]. In a survey carried out by Zimmer, et al. [2] among 120 American participants, there was a high degree of public acceptance and understanding of dental implants, and also a general positive mindset towards dental implants [2]. Understanding what consumers know about implants helps to balance patient desires with what can be done objectively and prevent a negative image of implant dentists created by communication disparity and customer frustration [3].

A recent breakthrough in survey methodology has been the introduction of web-based survey (one of the most commonly used survey methods). Web-based survey has been more prevalent in areas such as appraisal analysis than paper-based survey. Online survey is the collection of large volumes of information by self-administered electronic sets of web-based questions without needing to pay for interviewees, paper materials or advertisements and does not require additional data entry to process feedback. The increase in web-based survey is due to the growing usage of electronic media and the aim of this study is by using webbased survey technique to assess public awareness of dental implants.

\section{Material and Methods}

\section{Study Design and Study Population}

The aim of the self-explanatory questionnaire was to determine the perception, awareness of patients toward dental implants as a treatment modality among the general population of Punjab and to assess attitude on accepting dental implants as a treatment modality. A web-based survey was performed using a survey application (prepared in Google forms software) composed of 12 questions and evaluated using percentage in order to evaluate dental implant awareness among 250 participants distributed through social networking platforms like whatsapp and facebook with 20-60 years of age for two weeks in April 2020. Questionnaire was designed in English to help the respondents complete the questions and get a good sense of them. Questionnaires could be accessed via computer / laptop / smartphones. A web-based assessment helped to promote data collection, data processing and statistical research maintenance. The added benefits were cost savings, and processing time was reduced. The data collected from an online form was readily accessible and could easily be converted for further analysis into specialized statistical programs or spread sheets. Chi-square test was used to study the association between demographic variables and awareness about dental implant. Statistical package version 15 was used to analyze the data.

Inclusion requirements were Persons between 20 and 60 years of age with a well-educated subject (computer proficient and able to comprehend implant-related issues). Exclusion criteria were persons under 20 years of age and over 60 years of age and those who had no digital skills and understanding of implant-related issues. The survey method contained self-explanatory questions undertaken by AmitP, et al. [4] and Chowdhary R, et al. [5]. We analysed the allocation of responses using percentages and frequencies. Descriptive statistical analysis was addressed for questionnaire scores.

\section{Results}

The study was undertaken consisting of 151 males (62.9 percent) and 89 females (37.1 percent). The participants' age range was $20-60$ years, with a majority ( 47.3 percent) in the 36-50 year age group. Graduation and above is the education standard of 96 (39.9 percent) participants (Table 1).

\begin{tabular}{|c|c|}
\hline Characteristics & Frequency (\%) \\
\hline Sex & \\
\hline Male & $151(62.9)$ \\
\hline Female & $89(37.1)$ \\
\hline Total & $240(100.0)$ \\
\hline Age(Years) & $83(34.6)$ \\
\hline $20-35$ & $114(47.3)$ \\
\hline $36-50$ & $43(18.1)$ \\
\hline $51-60$ & $240(100.0)$ \\
\hline Total & \\
\hline Level of Education & $6(2.3)$ \\
\hline Illiterate & $3(1.1)$ \\
\hline Primary Education & $64(26.8)$ \\
\hline Secondary Education & $71(29.9)$ \\
\hline Diploma & $96(39.9)$ \\
\hline Graduation or more & $240(100.0)$ \\
\hline Total & \\
\hline
\end{tabular}

Table 1: Demographic characteristics of respondents of the survey. 
Although asked whether lost teeth should be replaced, 13.5 per cent felt the need existed only where there was a clear gap (esthetically brought into question), while 78.1 per cent felt the absolute need for prosthetic replacement. Prosthetic options knowledge point, with 92 percent of participants knowing about dental implants while only 8 percent did not know. A huge majority of the study population (87.5 per cent) preferred to learn more about it. As far as information sources are concerned, $11.7 \%$ of respondents received information from friends and family and $63.3 \%$ from dentists. Just 13.2 percent of the participants had it from electronic media such as television, radio and the Internet.

In regards to an implant's longevity, 42.6 percent felt the implant's average lifespan was 10 years, while 38.9 percent felt it lasted a lifetime. When asked about the care necessary to maintain implants, $53.1 \%$ felt that implants needed more maintenance than natural teeth, while $29.2 \%$ believed implants needed the same amount of care as natural teeth. When asked what their personal opinion about dental implants, 90.3 per cent were willing to opt for dental implants, while 58.4 per cent thought it was an expensive procedure. This is in keeping with the fact that a higher percentage (44.8 percent) of participants expressed poor maintenance as the main downside of dental implants. Others (27.4\%) felt rejection by the body was a disadvantage. The percentage of understanding was considerably higher amongst men $(\mathrm{P}<0.01)$ (Table 2) as compared to females and among those with a graduation and above level $(\mathrm{P}<0.01)$ (Table 3$)$.

\begin{tabular}{|c|c|c|c|}
\hline \multicolumn{3}{|c|}{ Do you know about Dental Implants as an option to replace missing teeth? } \\
\hline Male & Yes Frequency (\%) & No Frequency (\%) & Total \\
\hline Female & $137(90.7)$ & $14(9.3)$ & 151 \\
\hline Total & $84(94.4)$ & $5(5.6)$ & \\
\hline P-0.01 & $221(92)$ & $19(8)$ & \\
\hline
\end{tabular}

Table 2: Association between gender and awareness about dental implants.

\begin{tabular}{|c|c|c|c|}
\hline \multicolumn{3}{|c|}{ Do you know about Dental Implants as an option to replace missing teeth? } \\
\hline & Yes Frequency (\%) & No Frequency (\%) & Total \\
\hline Below Graduation & $131(90.9)$ & $13(9.1)$ & 144 \\
\hline Graduation and above & $90(93.7)$ & $6(6.3)$ & 96 \\
\hline Total & $221(92)$ & $19(8)$ & \\
\hline P-0.01 & & & \\
\hline
\end{tabular}

Table 3: Association between level of education and awareness about dental implants.

\section{Discussion}

Patient survey of the level of awareness of dental implants among the Indian public differs significantly from most other earlier studies. This survey provides information on the awareness of the participants and their need for more details concerning dental implants as an alternative to replace missing teeth in form of web based questionnaire. Interestingly, 13.5 percent of those questioned felt it was only necessary to replace missing teeth if gap was visible while 78.1 percent undoubtedly wanted it. This is in line opposite to a recently published survey, which indicates that 79 percent of the Swedish population thought it was not appropriate to replace it [6] but coincides with the result coined by Zimmer, et al. [2], Tepper, et al. [3], and Berge P, et al. [7], indicating the level of awareness as $77 \%, 70.1 \%$ and $72 \%$, respectively.
The high subjective awareness can be related to high socioeconomical status of the people in the region.

This survey showed that dentists were the main source of information on dental implants, followed by internet, family \& friends, internet and last but not least newspapers and magazines which congruence with Indian studies by Saha A, et al. [8] and Suprakash B, et al. [9] but does not match with study by Zimmer, et al. [2] and Berge, P et al. [7] which says media was the principal source of dental implant information. In contrast to, this is in agreement with Chowdhary R, et al. [5], Ravi K, et al. [10] all of which states that dentists as the main source of information. Eightyseven percent of respondents wanted extra dental implant knowledge. A high percentage of participants reported wanting more information on dental implants, particularly 


\section{Open Access Journal of Dental Sciences}

from their dentist (63.3 percent), which is similar to earlier studies findings $[3,7]$.

Most participants amply proven a profound understanding of implant-based treatment. About threefourths of the participants wisely responded back that the jawbone was where implants were anchored whereas gums were marked at 4.2 percent and 11.8 percent were not certain. Further findings show similar to previous studies regarding information on longevity, complications and implant maintenance which highlights the insufficiency of current information passed on by dentists to their patients $[3,7]$. In regards to an implant's longevity, 42.6 percent felt the implant's average lifespan was 10 years, while 38.9 percent felt it lasted a lifetime. This is in contrast to the studies conducted by Tepper, et al. [3], Akagawa Y, et al. [11], and Tomruk 0, et al. [12] where almost 46\%, 28\%, and $33 \%$ of the participants felt that implants lasted for a lifetime. Nearly 58.4 per cent of participants identified high costs as the single biggest implant care downside followed by the invasive nature of the procedure and a lengthy time for completion of the treatment. These results mimic earlier research [3,7]. 74.3 per cent of participants reported satisfaction with implant-based treatment. More patients will prefer for alternative therapies based on implants once their healthcare plans include protection for those treatments. Similarly, the Government should enforce initiatives to provide low socio - economic status patients with affordable dental implant-based possible treatments.

In addition, 90.3 per cent of those fully cognizant of dental implants agreed to undertake implant-based treatment upon being asked whether they would restore their lost teeth with implants. This clearly suggests that respondents will indeed to choose such treatment options to replace their lost teeth once they are familiar with implant-based treatments, and would probably be happy with the services provided. One similar study related to awareness of dental implants is conducted in Kuwait to test public understanding and perception of dental implants on randomly selected samples. In cross-sectional surveys 527 adult participants used a standardized questionnaire. This study revealed a high level of public awareness, but lack of knowledge on the procedural aspect [13] likewise study was conducted to evaluate patient awareness and attitude towards dental implants among Malaysians using self-explanatory survey and reported that 56 percent of Malaysians were aware of dental implants as an alternative to restoring missing teeth [14]. Small sample size with limited period is the limitation of this research. With web-based surveys, respondents can answer the questionnaire by entering their responses while connecting to the Internet looking for correct answers tut the positive part is that the answers are dynamically stored in the survey database, allowing for trouble-free data handling and less data error possibilities.

\section{Conclusion}

This study showed a high degree of public understanding on the possible benefits of dental implants to replace lost teeth. Particularly unique efforts are needed to improve awareness and knowledge among women and the citizenry with less education. Public sector efforts should be made to lower the expense of the implants to make them affordable to everybody. Online web survey was a faster way to collect data from the respondents compared to paper-based survey. This survey enables the collection of information from the target population at minimal price and quick. The results of this study need to be evaluated for a lengthy span of time by executing structured surveys that involve a larger population. In addition, it is crucial to consider how advanced technology (computer, laptop and smartphones) plays a significant role in carrying out online web survey studies with their own advantages and disadvantages.

\section{References}

1. Al Johany S, Al Zoman HA, Al Juhaini M, Al Refeai M (2010) Dental patient's awareness and knowledge in using dental implants as an option in replacing missing teeth: A survey in Riyadh, Saudi Arabia. Saudi Dent J 22(4): 183-188.

2. Zimmer CM, Zimmer WM, Williams J, Liesener J (1992) Public awareness and acceptance of dental implants. Int J Oral Maxillofac Implants 7(2): 228-232.

3. Tepper G, Haas R, Mailath G, Teller C, Zechner W, et al. (2003) Representative marketing-oriented study on implants in the Austrian population. I. Level of information, sources of information and need for patient information. Clin Oral Implants Res 14(5): 621-633.

4. Prasad A, Gharpure AS (2016) Awareness of dental implant treatment in an Indian metropolitan population. J Dent Implants 6(2): 62-68.

5. Chowdhary R, Mankani N, Chandraker NK (2010) Awareness of dental implants as a treatment choice in urban Indian populations. Int J Oral Maxillofac Implants 25(2): 305-308.

6. Palmqvist S, Soderfeldt B, Arnbjerg D (1991) Subjective need for implant dentistry in a Swedish population aged 45-69 years. Clin Oral Implants Res 2(3): 99-102.

7. Pommer B, Zechner W, Watzak G, Ulm C, Watzek G, et al. (2011) Progress and trends in patients' mindset on dental implants. I: Level of information, sources of 


\section{Open Access Journal of Dental Sciences}

information and need for patient information. Clin Oral Implants Res 22(2): 223-239.

8. Saha A, Dutta S, Vijaya V, Rajnikant N (2013) Awareness among patients regarding implants as a treatment option for replacement of missing teeth in Chattisgarh. J Int Oral Health 5(5): 48-52.

9. Suprakash B, Ahammed AR, Thareja A, Kandaswamy R, Nilesh K, et al. (2013) Knowledge and attitude of patients toward dental implants as an option for replacement of missing teeth. J Contemp Dent Pract 14(1): 115-118.

10. Kumar RC, Pratap KV, Venkateswararao G (2011) Dental implants as an option in replacing missing teeth: A patient awareness survey in Khamman, Andhra Pradesh.
Indian J Dent Sci 3(5): 33-37.

11. Akagawa Y, Rachi Y, Matsumoto T, Tsuru H (1988) Attitudes of removable denture patients toward dental implants. J Prosthet Dent 60(3): 362-364.

12. Tomruk OC, Kayahan OZ, Şençift K (2014) Patient's knowledge and awareness of dental implants in a Turkish subpopulation. J Adv Prosthodont 6(2): 133-137.

13. Al Musawi, Sharma P, Dasti M (2017) Public awareness and perception of dental implants in randomly selected sample in Kuwait. J Med Imp Surg 2(2): 116.

14. Kohil S, Bhatia S, Kaur A, Rathakrishnan T (2015) Patient awareness and attitude towards dental implants. Indian J Dent 6(4): 167-171. 